\title{
O SIMBÓLICO ENQUANTO PRODUTOR DE MEMÓRIA: UMA ANÁLISE DO CONTO OS GESTOS DE OSMAN LINS
}

\section{THE SYMBOLIC AS A PRODUCER OF MEMORY: AN ANALYSIS OF THE SHORTSTORY OS GESTOS BY OSMAN LINS}

Ribanna Martins de Paula ${ }^{1}$

RESUMO: Este artigo investiga os símbolos presentes no conto Os Gestos (2003), de Osman Lins, e como os mesmos são capazes de ativar a memória de seu personagem principal. Para tal, consideraram-se as contribuições teóricas acerca dos estudos sobre os símbolos conforme apresentadas por Jung (1964), Frye (1973), Eliade (1979) e Chevalier e Gheerbrant (1986), bem como as de Bergson (1999) relacionadas ao estudo da memória. Dessa forma, a presente pesquisa contribui para os estudos osmanianos e para a fortuna crítica da obra.

Palavras-chave: Símbolo; Memória; Osman Lins; Os Gestos.

ABSTRACT: This article investigates the symbols present in the short story Os Gestos (2003), by Osman Lins, and how they are capable of activating its main character's memory. To do so, there were considered the theoretical contributions regarding the symbolic studies as presented by Jung (1964), Frye (1973), Eliade (1979), and Chevalier and Gheerbrant (1986), as well as the ones by Bergson (1999) concerning the memory studies. Thus, this research contributes to the osmanianos studies and the work's critical fortune.

Keywords: Symbol; Memory; Osman Lins; Os Gestos.

\section{INTRODUÇÃO}

O presente artigo tem por objetivo investigar os símbolos presentes no conto $O s$ Gestos (2003), do escritor pernambucano Osman Lins, bem como analisar como estes são capazes de ativar a memória de André, protagonista da obra, ou estabelecer o diálogo entre passado e presente. Para tal, o aporte teórico deste trabalho busca relembrar

\footnotetext{
${ }^{1}$ Mestranda na área de Literatura Comparada na Universidade de Brasília (PósLIT/UnB) e Licenciada em Letras/Inglês pela mesma universidade. Desenvolveu pesquisas nas áreas de Psicologia Escolar, Literatura Comparada, Literatura e Outras Artes e Literatura Brasileira Contemporânea. Atualmente atua como pesquisadora bolsista do PósLIT/UnB. Tem experiência nas áreas de Línguas Estrangeiras, Linguística, Literatura e Educação. E-mail: ribanna.neuhaus@gmail.com
} 
conceitos relevantes atrelados aos estudos sobre o simbólico e da memória apresentados por Jung (1964), Frye (1973), Eliade (1979) e Chevalier e Gheerbrant (1986); e Bergson (1999), respectivamente. Quanto à metodologia, seus procedimentos técnicos são baseados no estudo bibliográfico dos teóricos apresentados, bem como do corpus literário deste artigo.

Ao fim deste trabalho, os resultados da análise apresentada tornam-se relevantes para aqueles que buscam aprofundar-se nos estudos da memória, em especial a individual, e a relação que esta possui com os símbolos que permeiam a vida do sujeito que recorda. De tal maneira, este artigo procura colaborar para o entendimento de conceitos e assuntos fundamentais para um melhor entendimento do personagem literário do conto, bem como contribui com os estudos literários da obra de Osman Lins, de maneira especial, Os Gestos (2003).

\section{Pensando o símbolo}

Em Anatomia da Crítica, Northrop Frye classifica o símbolo como "qualquer unidade de qualquer obra literária que possa ser isolada para a atenção crítica” (1973, p. 362) envolvendo, geralmente, unidades menores - imagens, frases, palavras, etc. - tendo como função expressar e atribuir significações dentro do texto literário. Frye afirma ainda que, no momento da leitura, a atenção do leitor aponta para duas direções distintas, sendo uma exterior e outra interior. Segundo o teórico:

Uma direção é exterior ou centrífuga, e nela ficamos indo para fora de nossa leitura, das palavras individuais para as coisas que significam, ou, na prática, para nossa lembrança da associação convencional entre elas. A outra direção é interna ou centrípeta, e nela tentamos determinar com as palavras o sentido da configuração verbal mais ampla que elas formam. Nos dois casos lidamos com símbolos, mas, quando ligamos um sentido exterior a uma palavra, temos, em adição ao símbolo verbal, a coisa representada ou simbolizada por ele (FRYE 1973, p. 77).

Assim, os símbolos presentes na literatura podem ser manifestados por meio da associação e lembrança remetidas por eles ou do sentido que determinada palavra representa.

Segundo Frye (1973), no estudo crítico-analítico da literatura, os símbolos não servirão somente como recurso para dar sentido ao texto, mas também como elemento de 
contexto, podendo relacionar - ainda que implicitamente - pessoas e objetos dentro do texto, ou até mesmo remeter a outras narrativas por meio de evocações capazes de ativar a memória do sujeito que lê, automaticamente. Ademais, os símbolos podem possuir mais de um significado diferente, estando sua compreensão condicionada à união entre o símbolo em si, bem como seu significado e o contex to em que é empregado.

Carl Gustav Jung, ao lançar-se a identificar o símbolo na psique humana, conceituou-o como aquilo que exprime algo figurado e difícil de decodificar. $O$ psicanalista, ao encarar o inconsciente como igual ao consciente - ou seja, real e essencial para o homem - afirma que os símbolos seriam elementos do inconsciente capazes de se comunicar com o consciente por meio dos sonhos que, segundo o autor, não poderiam ser interpretados empiricamente, mas de uma forma unicamente particular e pessoal.

Os símbolos selecionados pelo inconsciente de uma pessoa particular possuem significados que dizem respeito somente a ela. De acordo com Jung (1964), o símbolo é um termo, um nome ou uma imagem "que nos pode ser familiar na vida diária, embora possua conotações especiais além de seu significado evidente e convencional. Implica alguma coisa vaga, desconhecida ou oculta para nós” (JUNG, 1964, p. 16). Assim, para que algo seja considerado simbólico é necessário que ele possua conotações além de seu significado imediato.

Jung (1964) acreditava que, por haver várias coisas impossíveis de compreender, o uso frequente de termos simbólicos pelo homem teria como objetivo representar conceitos que estes não são capazes de definir completamente. Um exemplo seria a utilização de linguagem e imagens simbólicas pelas instituições religiosas - maiores usuárias de símbolos - como a cruz para o cristianismo.

Outro teórico a debruçar-se sobre o tema, Mircea Eliade - um dos mais influentes historiadores e filósofos das religiões da contemporaneidade -, em seu livro, Imagens $e$ Símbolos (1979), afirma que o pensamento simbólico precede qualquer linguagem e razão discursiva, uma vez que é consubstancial ao homem. Prova disso é a forma com que a humanidade submetia si mesma aos elementos da paisagem natural, animais, constelações, entre outras coisas visíveis, visando inserir-se no mundo dos fatos morais e espirituais.

Ao comentar o ponto de vista da psicanálise, Eliade (1979) explica que os símbolos e as imagens não são criados pela psique de modo irresponsável, porém são resultados de uma necessidade do homem, desempenhando o papel de revelar "certos 
aspectos da realidade - os mais profundos - que desafiam qualquer outro meio de conhecimento" (ELIADE, 1979, p. 13). Ainda sobre imagens e símbolos, o autor afirma "que se pode camuflá-los, mutilá-los, degradá-los mas que nunca se poderá extirpá-los" (ELIADE, 1979, p. 12), uma vez que estes pertencem à substância da vida espiritual, e assim, estudá-los propiciaria um melhor conhecimento do homem.

Contribuindo com os estudos sobre o simbólico, tem-se o essencial dicionário de símbolos de Chevalier e Gheerbrant (1986). Os autores defendem que objetos comuns podem adquirir valores simbólicos e significados ilimitados, independente da sua natureza natural ou abstrata. Dessa forma, uma vez que o símbolo possui sentidos múltiplos, cada representação simbólica é o centro de uma teia e a esta estão conectadas outras teias, cada uma com seus centros.

Além disso, no símbolo é produzido um fenômeno de condensação e, assim, um único símbolo é capaz de representar mais de um objeto e este, em uma cadeia infinita, funciona como representação de outros objetos. Entretanto, suas percepções são pessoais, pois o homem adiciona valores sociais e culturais adquiridos às suas próprias experiências.

Los símbolos fundamentales condensan la experiência total del hombre, religiosa, cósmica, social, psíquica (en los tres niveles inconsciente, consciente y supraconsciente): realizan tambien una sintesis del mundo mostrando la unidad fundamental de sus tres planos (inferior, terrestre y celeste) y el centro de las seis direcciones del espacio; desplegando grandes ejes de reagrupamiento (luna, agua, fuego, monstruo alado, etc); en fin, enlazan al hombre con el mundo, los processos de integración personal del primero se insertan en una evolución global, sin aislamiento ni confusión (CHEVALIER \& GHEERBRANT, 1986, p. 27).

Por fim, pode-se afirmar que o repertório pessoal do indivíduo é importante uma vez que auxilia na compreensão de um símbolo. Sendo este subjetivo e sugestivo, ao analisa-lo é essencial considerar todos os domínios referentes à concepção de representação simbólica, unindo a compreensão do papel significativo do símbolo em questão às interpretações de seus múltiplos e variados sentidos. É a isto que se propõe a análise realizada no presente artigo em relação ao personagem André de Os Gestos (2003).

\section{Pensando a memória}


Ao debruçar-se sobre o estudo da memória, Henri Bergson (1999) destaca o processo corpo/imagem como principal meio pelo qual a memória constitui-se em agente de criação de subjetividades. Neste processo, o autor afirma que o corpo possui uma posição privilegiada em relação às imagens e objetos que o cercam, pois é por meio do corpo que o homem estabelece diferentes formas de ação. Ademais, o corpo exerce o papel de componente ativo na relação imagens/subjetividades.

Bergson afirma que "tudo se passa como se, nesse conjunto de imagens que chamo universo, nada se pudesse produzir de realmente novo a não ser por intermédio de certas imagens particulares, cujo modelo me é fornecido por meu corpo" (BERGSON, 1999, p. 12). Assim, é por meio do corpo que os objetos e as relações com o mundo são criados de forma subjetiva. Uma vez que os fatos e acontecimentos que configuram a maneira com que o indivíduo se relaciona em sociedade e com outros objetos - sua ação sobre as coisas - são provenientes da memória, imagem também é memória. O autor identifica e distingue a imagem em dois tipos: imagem-ação e imagem-lembrança.

Imagem-ação - que age e reage com o corpo - é caracterizada como o tipo de imagem que, além de reconhecer uma atividade passada da vida de um indivíduo, também recria este passado. Dessa forma, as imagens-ação tem uma atitude voltada para o presente, porém um presente capaz de criar o passado por meio da memória - um presente sensível. Este tipo de imagem origina-se na consciência de um passado capaz de registrar as ações do homem e está ligado à necessidade de remontar as percepções de outrora. Portanto, as imagens-ação não são responsáveis pela representação do passado, mas pela encenação da vida.

Imagem-lembrança, por sua vez, é aquela que, após o salto ontológico pelo qual o homem coloca-se no passado, passa do estado virtual ao atual, em outras palavras, da ontologia à psicologia. Sobre isso, Bergson proclama que “[...] nossa lembrança continua em estado virtual; dispomo-nos assim apenas a recebê-la adotando a atitude apropriada. Pouco a pouco aparece como que uma nebulosidade que se condensasse; de virtual ela (lembrança) passa ao estado atual” (BERGSON, 1999, p. 156).

Esse tipo de imagem refere-se às condições psicológicas da relação entre corpo e matéria - conjunto de imagens que cercam o homem - dando especial relevo ao papel desempenhado pela memória. Esta atua como regente de todo o processo do qual permanecem ativos o passado e o presente. Além disso, por meio das imagens-lembrança 
há “o reconhecimento inteligente, ou melhor, intelectual, de uma percepção já experimentada; nela nos refugiaríamos todas as vezes que remontamos, para buscar aí uma certa imagem, a encosta de nossa vida passada" (BERGSON, 1999, p. 88), ou seja, identifica-se somente parte inteligível da relação com os objetos, propiciando sua comunicabilidade.

Por fim, a memória humana pode ser compreendida como passado/presente coexistente, uma vez que há o reconhecimento do passado nas imagens-lembrança e a projeção do presente nas imagens-ação. A esse processo comunicativo, Bergson (1999) denominou "duração", responsável por expressar a maneira com que o homem se posiciona no tempo e espaço e onde se gera neste o reconhecimento de suas ações cotidianas, bem como sobre suas comunicações - imagens -, visto que o homem procura a inteligibilidade das coisas no passado e sua maneira de agir sobre elas no presente. Dessa forma, a ideia de duração deve ser considerada na análise de Os Gestos (2003), pois é durante este processo que o protagonista se encontra na narrativa.

\section{Relação entre símbolo e memória no conto}

O personagem protagonista do conto é André, um homem idoso que tem sua habilidade de falar destruída por conta de uma doença não especificada no texto. Assim, ele passa seus dias no quarto, dependente de sua esposa e filhas, com as quais só pode comunicar-se por meio de gestos. Dessa forma, o conto narra a rotina de André, suas relações sociais, bem como o estado psicológico e emocional do personagem que evoca memórias de sua juventude e coloca passado e presente em constante diálogo - por meio de imagens simbólicas. Portanto, com o objetivo de organizar esta análise, os dez símbolos $^{2}$ identificados e investigados serão discutidos na ordem em que aparecem na narrativa.

O primeiro símbolo encontrado, considerado o principal do conto, é a janela. É por meio dela que André começa a evocar memórias boas há muito esquecidas, como ele próprio afirma ao dizer que "durante minutos, ficou a olhá-la e sentiu que a sua grave serenidade o envolvia, trazendo-lhe um bem-estar como não senti há muito" (LINS, 2003, p. 31). Isso se dá, pois, a imagem da janela simboliza - conforme exposto por Chevalier

\footnotetext{
${ }^{2}$ Destacados por grifo próprio com o objetivo de facilitar a leitura e compreensão da análise.
} 
e Gheerbrant (1986) em seu dicionário - a receptividade e a abertura para as influências vindas de fora, e no caso de André este se torna receptivo à memória que está prestes a envolvê-lo, proveniente de fora de seu presente.

A próxima vez em que a memória do personagem for evocada será por meio dos símbolos de pássaros voando, céu cinzento e ondas, conforme a seguinte citação explicita:

Um casal de pássaros esvoaçou, além da árvore, dando a impressão de que as asas tocavam o céu cinzento, levantando um ondular de ondas que se cruzaram e extinguiram-se. A ilusão embalou-o: durante segundos, achou-se debruçado ante uma paisagem lacustre, vinculada à sua juventude (LINS, 2003, p. 32).

Os pássaros voando representam a alma em busca da superação de conflitos. O céu simboliza o espírito, enquanto a cor cinza evoca tristeza e melancolia. As ondas, por sua vez, representam "las irrupciones repentinas de lo inconsciente, otra masa de orden psíquico [...] lanzada por las pulsiones instintivas al asalto del espíritu, del yo pilotado por la razón" (CHEVALIER \& GHEERBRANT, 1986, p. 774). Assim, a lembrança de sua juventude revela-se como a única solução para sua inquietação, pois esta é capaz de romper o estado melancólico em que André se encontra.

A próxima memória é especialmente interessante, pois sua ativação ocorre por meio de símbolos relacionados a dois personagens do conto: a mulher de André e seu amigo, Rodolfo. Ao ser visitado por Rodolfo, a mulher de André impede seu encontro alegando estar o marido muito cansado e dormindo, o que causa agitação no protagonista, uma vez que é seu desejo receber o amigo de tantos anos. Ao narrar o ocorrido, André reflete sobre a cena:

[...] e o homem indagava se era a sua vitalidade ou a roupa branca o que o fazia repousante. Rodolfo lembrava um marinheiro, sua presença tinha uma amplitude de viagens. Como era diferente daquela mulher por trás dele, em seu vestido escuro, fria e vigilante, pronta a insinuar que a visita se alongava! (LINS, 2003, p. 33).

As imagens destacadas são branco, marinheiro (mar) e escuro (preto). A primeira está relacionada à ideia de juventude, início da vida, enquanto a segunda representa aquele que navega pelo mundo, pelo coração humano enquanto lugar de paixões - definiçãa simbólica do mar, segundo Chevalier e Gheerbrant (1986). Ambos os 
símbolos são identificados em Rodolfo que traz à memória de André sua vitalidade e liberdade de tempos passados. Em contrapartida, há o terceiro símbolo identificado na esposa do personagem. Escuro/preto, afirmam os teóricos em seu dicionário, são interpretados como representações da morte, fim da vida ${ }^{3}$ - situação em que André se considera estar. Assim, Rodolfo e a mulher simbolizam a intersecção entre seu passado e presente.

Após o evento narrado, André encontra-se sozinho novamente até começar a chover e vislumbrar Rodolfo fugindo para não molhar-se. Ele é interrompido pelas filhas que o enchem de perguntas e André, não sendo capaz de respondê-las, brutalmente as afasta, e suas formas e barulhos "[...] dispersaram-se e mergulharam na chuva, que as dissolveu" (LINS, 2003, p. 34). Para Chevalier e Gheerbrant (1986), a chuva simboliza água abençoada e purificadora enviada do céu e é ela que propicia o mergulho de André em uma memória feliz de sua infância, na qual as mesmas bênçãos estão presentes na forma de poças.

Ele corre na manhã invernal, os pés descalços cortando poças de água. A prima chama-o, à janela; voam cabelos sobre o rosto infantil, que sorri. A viagem do barco de papel repousa nas mãos da menina. Ele toma-o, curva-se, entrega-o à enxurrada. Nascem veleiros, alvíssimos, libertos no mar (LINS, 2003, p. 34).

Mais uma vez vê-se a presença da figura do mar, indicando a liberdade possuída por André, que agora está perdida.

Os últimos símbolos responsáveis por ativar a memória do protagonista que foram investigados na narrativa são a luz e o vento. Estes se fazem presente no excerto em que André está contempla sua filha mais nova, Mariana, transformar-se ante seus olhos:

Mariana estava de costas para a janela [...] Por trás dela, na linha exterior das fasquias, cintilavam gotas de água; [...] Uma claridade opalina subia do pescoço, tocava o queixo na moça, banhava sua face direita e extinguia-se na penugem da fonte. $O$ resto das feições mal se percebia; [...] A parte do colo sobre que incidia a luz pálida, fremiu, palpitou, [...] Soprou um vento forte, que precipitou seus cabelos e precipitou o tombar das gotas de água. Ela moveu a cabeça em direção à luz, lenta, com um suspiro ansioso. $\mathrm{O}$ rosto era belo e se renovava, como um ser adormecido que enriquecesse no deslumbramento de um sonho (LINS, 2003, p. 37-38).

\footnotetext{
${ }^{3}$ A depender do contexto cultural.
} 
A luz "se pone en relación con la obscuridad para simbolizar valores complementarios o alternantes de una evolución" (CHEVALIER \& GHEERBRANT, 1986, p. 663) - das trevas à luz. Também é associada à elevação do ser. No trecho selecionado acima, Mariana está de costas para a janela - abertura para as influências vindas de fora -, porém sobe uma claridade por seu corpo, revelando alguns de seus aspectos, enquanto outros ainda estão obscuros. Tudo muda quando o vento representação de sopro e influxo espiritual de origem celeste - a atinge, fazendo com que gotas da chuva - bênção e purificação - caiam sobre a moça que, então, volta-se para a luz. Assim, Mariana se renova, eleva e evolui de criança para jovem mulher - o passado e o presente mais uma vez em diálogo - deixando André deslumbrado com o processo.

\section{CONSIDERAÇÕES FINAIS}

Após a conclusão desta pesquisa, infere-se que um dos tópicos trabalhados em $O s$ Gestos (2003) é a presença contínua do passado de André em seu presente, e que muitas vezes essa memória é evocada por meio de símbolos. Torna-se importante destacar, também, a passagem de Mariana da infância à adolescência - passado e presente -, pois este momento propicia profunda reflexão em André, que presencia o processo. $\mathrm{O}$ personagem percebe então que o tempo é fugaz e sua passagem muitas vezes despercebida.

Tendo em vista o arcabouço teórico da pesquisa, muitos dos símbolos presentes na narrativa são responsáveis pela evocação de memórias passadas relacionadas diretamente à juventude de André, seus tempos de liberdade e de glória, bem como de sua desolada percepção do presente, onde se encontra doente e desesperançado de cura. Ademais, o corpus deste trabalho apresenta uma relação muito tênue entre passado e presente, uma vez que elas são muitas vezes confundidas na narrativa - ora o narrador está no presente, ora no passado. De uma forma geral, pode-se dizer que Os Gestos (2003) é um conto que possibilita ao leitor extrair uma reflexão sobre a efemeridade do tempo. 


\section{REFERÊNCIAS}

BERGSON, Henri. Matéria e memória: ensaio sobre a relação do corpo com o espírito. Tradução de Paulo Neves. São Paulo: Martins Fontes, 1999.

CHEVALIER, Jean; GHEERBRANT, Alain. Diccionarios de los símbolos. Tradución de Manuel Silvar y Arturo Rodríguez. Barcelona: Helder, 1986.

ELIADE, Mircea. Imagens e símbolos. Tradução de Maria Adozinda Oliveira Soares. Lisboa: Arcádia, 1979.

FRYE, Northrop. Anatomia da crítica. Tradução de Péricles Eugênio da Silva Ramos. São Paulo: Cultrix, 1973.

JUNG, Carl J. O homem e seus símbolos. Tradução de Maria Lúcia Pinho. Rio de Janeiro: Nova Fronteira, 1964.

LINS, Osman. Melhores contos de Osman Lins. São Paulo: Global, 2003.

Recebido em: 14 abr. 2018

Aceito em: 05 jun. 2018 